Research Paper

\title{
ANALYSIS OF CRITICAL WEATHER PATTERNS CAUSED SEVERE FLOODING AND SPATIAL, TIMING RAINFALL DISTRIBUTION ON THE MA RIVER BASIN
}

\author{
NguyenTien Kien ${ }^{1}$
}

\author{
ARTICLE HISTORY \\ Received: February 20, 2020 Accepted: April 20, 2020 \\ Publish on: April 25, 2020
}

\section{ABSTRACT}

Ma River is the biggest in the Central of Viet Nam with the length of $512 \mathrm{~km}$ and stretching over two latitudes and longitudes, therefore, the basin's meteorological and hydrological regime is very complicated. The current situation of hydro-meteorological network in the basin is unevenly distributed with a high density in the downstream, sparse or not in the upstream particularly a part of basin belongs Lao PDR's territory that are challenges for flood forecasting and hydrological research. The contents of this paper will summarize, synthesize main natural geographic characteristic, meteorological, hydrological features, main weather conditions, causes of flood formation as well as analysis of monthly rainfall distribution which based on the long-term historical data. All of these will be indispensable information for developing of flood forecast approach or further hydrological researching for the Ma River basin in the future. Besides, some comments and suggestion are proposed in order to partially surmount the spatial rainfall data gap in the Ma River basin.

Keywords: Ma River basin, flood formation causes, rainfall distribution.

$\triangle$ NGUYEN TIEN KIEN

Corresponding author: kien.wrs@gmail.com

${ }^{1}$ National Center for Hydro-Meteorological Forecasting

\section{Introduction}

Rainfall data is the most important data source in the fields of hydrological researches and forecasts. Such data are recorded as observational data through comprehensively designed rainfall station networks. However, rainfall records are often incomplete because of missing rainfall data in the measured period, insufficient or without rainfall stations in the research areas. To resolve the problems of such partial rainfall data, probable rainfall data can be estimated through spatial interpolation techniques. Various spatial interpolation techniques have already been employed in related fields. Such techniques can be divided into geographical statistics and non-geographical statistics. Examples include nearest neighbor $(\mathrm{NN})$, Thiessen polygons (THI), splines and local trend surfaces, global polynomial (GP), local polynomial (LP), trend surface analysis (TSA), radial basic function (RBF), inverse distance weighting (IDW), and geographically weighted regression proposed by Fotheringham et al. (2002), which are all classified as non-geographical statistics. On the other hand, various forms of Kriging method are classified as geographical statistics (Lam, 1983; 
Jeffrey et al., 2001; Price et al., 2000; Li and Heap, 2008; Yeh et al., 2011).

Several commonly used spatial interpolation estimation methods in hydrological forecast and calculation synthesized by Sarann Ly et al include:

The simplest and most common spatial interpolation method, particularly in relatively flat zones, is to use the simple average of the number of stations. However, use of this method has decreased because it does not provide presentative measurements of rainfall in most cases (Chow, 1964).

The Thiessen polygon method assumes that the estimated values can take on the observed values of the closest station. The THI method is also known as the nearest neighbor $(\mathrm{NN})$ method (Nalder et al., 1998). The method requires the construction of a THI network. These polygons are formed by the mediators of segments joining the nearby stations to other related stations. The surface of each polygon is determined and used to balance the rain quantity of the station at the center of the polygon. The polygon must be changed every time a station is added or deleted from the network (Chow, 1964). The deletion of a station is referred to as "missing rainfall". This method, although more popular than taking the simple average of the number of stations, is not suitable for mountainous regions, because of the orographic influence of the rain (Goovaerts, 1999).

The Inverse Distance Weighting method is based on the functions of the inverse distances in which the weights are defined by the opposite of the distance and normalized so that their sum equals one. The weights decrease as the distance increases.

Since the power of the inverse distance function must be selected before the interpolation is performed. A low power leads to a greater weight towards a grid point value of rainfall from remote rain gauges. As the power tends toward zero, the interpolated values will approximate the areal-mean method, while for higher levels of power, the method approximates the Thiessen method (Dirks et al., 1998). There is a possibility of including in this method elevation weighting along with distance weighting, Inverse Distance and Elevation Weighting (IDEW). IDEW provides more suitable results for mountainous regions where topographic impacts on precipitation are important (Masih et al., 2011).

In the polynomial interpolation (PI) method, a global equation is fitted to the study area of interest using either an algebraic or a trigonometric polynomial function (Tabios et al., 1985).

The spline interpolation method is based on a mathematical model for surface estimation that fits a minimum-curvature surface through the input points. The method fits a mathematical function to a specified number of the nearest input points, while passing through the sample points. This method is not appropriate if there are large changes in the surface within a short distance, because it can overshoot estimated values (Ruelland et al., 2008).

The Moving Window Regression (MWR) method is a general linear regression, which is conducted only in areas where a relationship between the primary and secondary variables is thought to exist (Lloyd, 2005).

Ma River is the biggest in the Central of Viet Nam covering $28400 \mathrm{~km}^{2}$ in which $10200 \mathrm{~km}^{2}$ is belong Lao PDR territory. Ma river flow throught Viet Nam provinces as Son La, Hoa Binh, Nghe An, Thanh Hoa and Sam Nua of Laos with total lenght of $512 \mathrm{~km}$ and complicated hydro-meteorological characteristics. Ma River flows through five Vietnam's provinces of Lai Chau, Son La, Hoa Binh, Nghe An, Thanh Hoa and Sam Nua of Laos PDR. The hydro-meteorological network is limited and unevenly dis- 
tributed in the river basin with a high density in the downstream, sparse or not in the upstream where located rugged mountainous and a part of basin in Laos. These are challenges for hydrological forecasting for Ma River basin management, especially for the upstream and middle parts that do not have much hydro-meteorological data.

So far, there have been many researches and projects in the field of water resource management and hydrology for the Ma River, which have contributed significantly to disaster prevention and met the requirements of economic development in the basin.

Project of "Integrated planning on water resources of Ma river basin" from 2002 to 2005, by senior engineer Tran Van Nau, Institute of Water Resources Planning (IWRP) as the leader. The project was implemented in collaboration with the lead agency of the IWRP and other offices such as the Thanh Hoa Irrigation Planning Delegation, the DARDs of 4 provinces of Thanh Hoa, Hoa Binh, Son La and Lai Chau aims to study the master plan for water resources development for the Ma River basin covering 04 provinces of Vietnam: Thanh Hoa, Hoa Binh, Son La, Lai Chau and the part of basin belong Lao PDR.

Studies by Hoang Ngoc Quang et al named: "Studying and assessment of the water balance for the downstream of Ma River with consideration of Cua Dat and Thac Quyt reservoirs" under Hydrological and Meteorological Administration research project in 2001-2002 and "Research on integrated management of natural resources and environment of the Ma River basin" from 2006 to 2008 belongs to a research project of the Ministry of Natural Resources and Environment. With the study of water balance assessment of Ma River basin, the author studied and calculated the water balance in the system to make recommendations on management, ex- ploitation and use of natural resources in the river basin to overcome water shortages and calculate optimally and effectively use water sources economically. In the content of ministerial-level project, the author focused on synthesizing water resources and environment in $\mathrm{Ma}$ river basin belong Thanh Hoa province to serve basin management, natural disaster prevention and environmental protection.

A scientific topic "Study on rational use of natural resources and disasters prevention in the Ma River basin” in 2008-2009 by Vu Thi Thu Lan of the Institute of Geography as the leader. The objective of the study is related to assess the current status and evolution of natural resources (land and water) in the Ma River basin, identify the causes and forecast the impact of natural resource degradation and natural disasters.

In general, most of research projects implemented for the Ma River basin mainly focused on fields of water resource management and plan, hydropower impacts on river flow and the most study areas are downstream and lower reaches of river system, where has a high density of hydro-met network and abundant data sources. And so far, there are not many researches taking into account for upper and middle parts of the basin, in which, these areas mainly located inmountainous areas of Lai Chau, Son La provinces and Laos areas due to the lack or without both information and hydro-meteorological observation.

In river basin research and hydrological forecasted operation, the deep understanding of river basin characteristics, flood flow regime, relationship of rainfall - runoff in the river basin is very important and indispensable information. Therefore, the report "Analysis of critical weather patterns caused severe flooding, spatial and timing rainfall distribution on $\mathrm{Ma}$ river basin" focus on synthesizing information of the natural geographic characteristics of the river 
basin, meteorological features, weather patterns causing heavy rainfall - severe flooding, main causes of flood formation and analyzing rainfall distribution following spatial and timing to support the development of flood forecasting and warning approaches or simulated modelling for Ma river.

\section{Materials and methods}

\subsection{Description of study area}

\subsubsection{Topographic characteristics}

The topography of the Ma river is very diverse due to the basin extending from the Northwestern mountain through Laos to the high mountains of Truong Son to the shores of the Tonkin Gulf. The general slope of the basin from the Northwest to the Southeast. The topography of Ma River can be divided into 3 types:

High mountainous terrain: The topography is mainly located in the upstream of the Ma river belong the Northwestern of Viet Nam and Lao's territory.

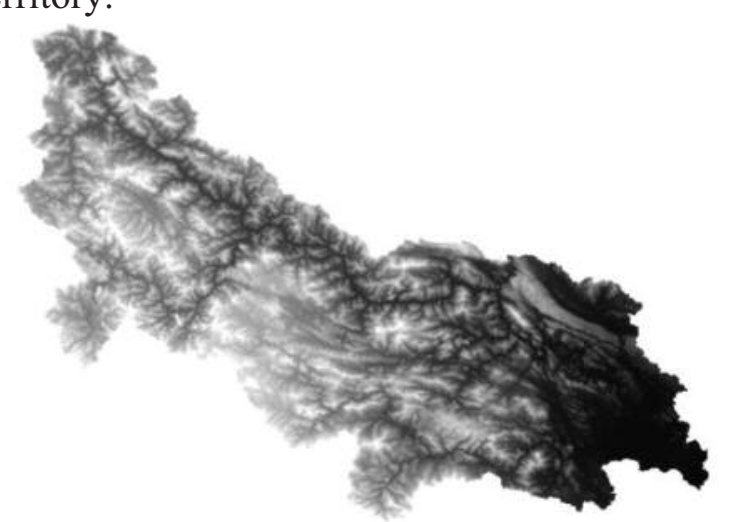

Fig. 1. Elevation mapping of Ma river

Low mountainous and midland terrain: This type of topographic feature cover almost middle reach of Ma river, Am and Buoi River basin with the area of 3,305 $\mathrm{km}^{2}$ (accounting for $11.75 \%$ of the whole basin area).

Delta and coastal zone: Downstream of $\mathrm{Ma}$ river from Cam Ngoc, Kim Tan and Bai Thuong back to the mouth of the delta river is quite flat with the elevation from $20 \mathrm{~m}-0.5 \mathrm{~m}$ in the coastal area. Lower delta is divided by distributaries such as Len and Cao river.

\subsubsection{River network}

The Ma river basin have specific morphologies as river network density of $0.66 \mathrm{~km} / \mathrm{km}^{2}$, meandering coefficient of 1.7; shape coefficient of 0.17 ; asymmetric coefficient of the basin is 0.7 . The average slope of the basin is $17.6 \%$; the narrowest point is $42 \mathrm{~km}$, Ma river has 39 main tributaries level 1, two important distributaries: Len River and Lach Truong River on the left bank.

The morphological characteristics of the Ma river clearly show the characteristics of a mountainous river with narrow river beds and high waterfall. This is a young river, digging, invading not enough time to form an average profile. The average slope of the river bed is around 1.050/00. Table 1 summarizes morphological characteristics of mainstream and large river in the Ma River basin and the basin elevation is illustrated in Fig 2.

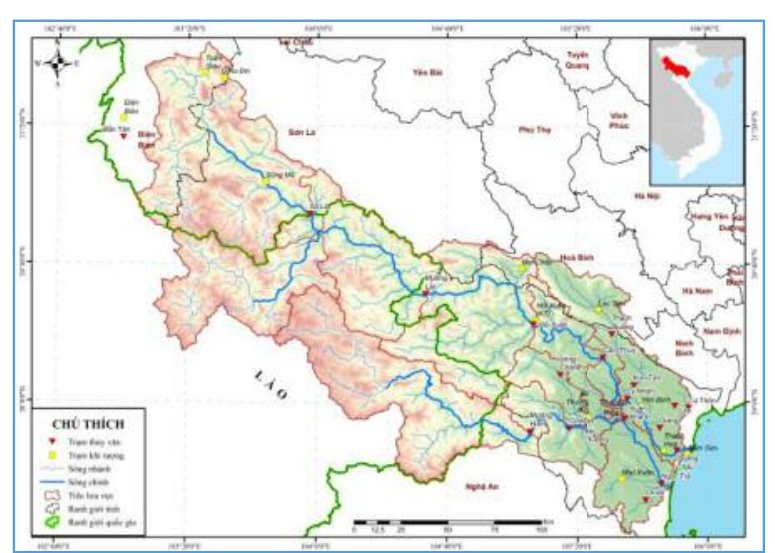

Fig. 2. River basin and Hydro-Met stations network in the Ma River

\subsubsection{Overview of meteorological and hy-} drological characteristics

Located in tropical mooson area, rainny season of the river basin closely relate to southeast and southwest mooson activities from May to October with storms, tropical depresssion, hotwet weather. Dry season is associated with the 
northeast monsoon period from December to April. There are three main rainfall regime characteristics: north eastern of northern part of Viet Nam for upstream of the Ma river; Northern Central rainfall regime for Chu river basin - a main tributary of Ma River; northern delta rainfall regime for downstream.

The flow on Ma river basin is dependent on rainfall regime which is divided into two distinct seasons: flood season starting at end of June and ending in October, dry season from November to June. The maximum values of monthly flow is recorded in August at upstream and in September at downstream positions, accounting for 19\%-22\% of the annual flow. The duration of biggest flow aprearance is in July, August and September, accounting for $53-54 \%$ of the annual flow.

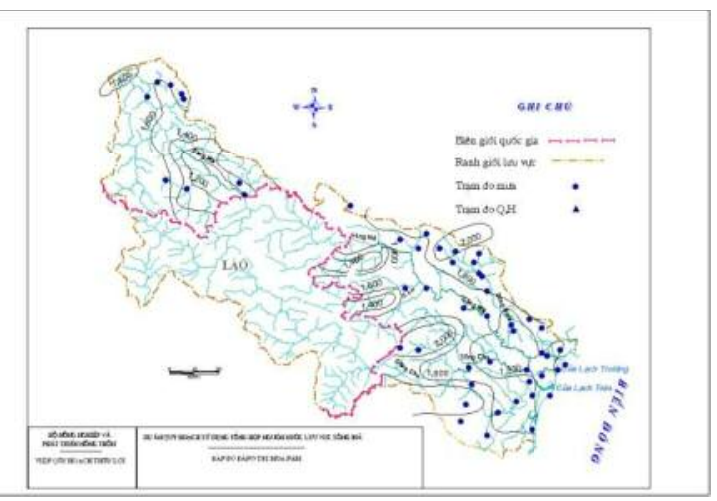

Fig. 3. Annual flow distribution on Ma river basin

\subsection{Data collection}

Hydro-met data collected for analysing in the report is the historical water level and rainfall during the last 15 years (2000 - 2015) from 25 rain gauges and 9 water level stations: Hoi Xuan, Cam Thuy, Ly Nhan, Giang (on the Ma River mainstream), Cua Dat, Bai Thuong, Xuan Khanh (on the Chu River), Thach Quang, Kim Tan (on the Buoi River).

Based on the statistics, 21 flood events on Ma river basin from 2000 to 2015 were selected for analysing in the report which have flood amplitude at Cam Thuy station on mainstream over $3 \mathrm{~m}$ or the flood peaks reached flood stage.

\subsection{Methodology}

Methods of synthesis and analysis: Based on information of flood occurrences in the Ma river basin during 2000 and 2015, major floods were selected, synthesized and classified following the main formation causes of heavy rainfall - flood ing and were grouped statistics as the same condition. From historical time series of hydro-meteorological data including rainfall and water level, the author determinated average monthly rainfall at ground observed stationsin the river basin in order to assess rainfall distribution by the time and the space.

Spatial interpolation method: The distribution of hydro-meteorological station network in $\mathrm{Ma}$ river basin is uneven with the sparse density in the upper and middle reaches of the basin and no data in the part belong Laos territory. To solve the problem of insufficient measuring and uneven distribution network, spatial interpolationis an effective method to estimate rainfall data in the river basin and is a common application in hydrology. There are many methods of interpolation techniques which can be divided into geographic and non-geographic statistics. Following Fotheringham et al. (2002), the statistical methods of estimating spatial rainfall can be mentioned as: nearest station based interpolation (Nearest Neighbor), Thiessen polygons, interpolation by straight lines and by region, by global polynomial (GP), by regional polynomial (LP), by trend analysis by surface (TSA), basic radial function (RBF), by inverse distance weight (IDW) and geographic weight regression. In this report, the nearest station-based interpolation method is be used for process analysis. 
Table 1. Morphological characteristics of large river basins in the Ma river basin

\begin{tabular}{|c|c|c|c|c|c|c|c|c|c|c|c|}
\hline No. & Basin & $\begin{array}{c}\text { Area } \\
\left(\mathrm{km}^{2}\right)\end{array}$ & $\%$ Area & $\begin{array}{c}\text { River } \\
\text { Length } \\
(\mathrm{km})\end{array}$ & $\begin{array}{c}\text { Mean } \\
\text { Elevation } \\
(\mathrm{m})\end{array}$ & $\begin{array}{l}\text { Mean Width } \\
(\mathrm{km})\end{array}$ & $\begin{array}{c}\text { Basin } \\
\text { average } \\
\text { Slope }(\% \text { ) }\end{array}$ & $\begin{array}{c}\text { River network } \\
\text { density } \\
\left(\mathrm{km} / \mathrm{km}^{2}\right)\end{array}$ & $\begin{array}{c}\text { Asymmetric } \\
\text { coefficient }\end{array}$ & $\begin{array}{c}\text { Basin shape } \\
\text { coefficient }\end{array}$ & $\begin{array}{c}\text { Meandering } \\
\text { coefficient }\end{array}$ \\
\hline & Ma River & 28,400 & 100 & 512 & 762 & 68.8 & 17.6 & 0.66 & 0.32 & 0.17 & 1.79 \\
\hline 1 & Nam Khoai & 1640 & 5.77 & 62.5 & 890 & 29.7 & 18.0 & - & -0.17 & 0.54 & 1.45 \\
\hline 2 & Nam Thi & 705 & 2.48 & 47.5 & 984 & 18.1 & 19.3 & - & -0.57 & 0.46 & 1.28 \\
\hline 3 & Nam Cong & 893 & 3.14 & 52.0 & 1233 & 19.9 & 16.4 & - & -0.16 & 0.22 & 1.58 \\
\hline 4 & Luong river & 1580 & 5.56 & 102 & 532 & 17.6 & 19.6 & - & 0.19 & 0.20 & 1.27 \\
\hline 5 & Lo river & 1000 & 3.52 & 76.0 & 615 & 13.9 & 20.4 & - & -0.33 & 0.19 & 1.35 \\
\hline 6 & Buoi river & 1790 & 6.30 & 130 & 217 & 16.1 & 12.2 & 0.59 & 0.16 & 0.14 & 1.53 \\
\hline 7 & Cau Chay & 551 & 1.94 & 87.5 & 114 & 8.0 & 5.4 & 0.47 & 0.01 & 0.12 & 1.62 \\
\hline 8 & Chu river & 7580 & 26.7 & 325 & 790 & 29.8 & 18.3 & 0.98 & -.014 & 0.12 & 1.58 \\
\hline
\end{tabular}

\section{Results and discussion}

\subsection{Main critical weather patterns causing heavy rainfall - severe flooding}

3.1.1. Weather conditions caused heavy or extreme rainfall in the Ma basin

Based on historical hydro-met data statistics in the Ma river basin from 2000 to 2015, 21 flood events with flood amplitude at Cam Thuy over $3 \mathrm{~m}$ were selected for analysing and synthetizing critical weather patterns as the main causes of heavy rainfall - severe flooding during 21 flood event occurrences: 1) the storms and tropical depressions (single or combination with other weather conditions) were recorded in 17 flood events (accounting for 39\%); 2) low-pressure trough or low pressure zone existed in the Northern part of Viet Nam as the main causes of 18 flood events (accounting for 41\%); 3) the inter-tropical convergence zone ITCZ were recorded as results of 7 flood events corresponding to $16 \%$.

In addition, other weather conditions such as strong southeast winds, combination of cold air with other weather patterns also were caused significant rainfall in the river basin. Detail information of flood events and main weather patterns as results of heavy rainfall is summarized in Table 2.

Among types of natural disasters, storms and tropical low pressures are caused not only heavy rainfall but also are largest devasting for provinces in the river basin. Due to geographical features, the downstream of Ma river flows through two provinces of Nghe An and Thanh Hoa in central of Viet Nam, where is frequently affected by storms in the East Sea, especially ap- pearing from July to September in the year. It can take a look at several significant information about typhoons, tropical storms or tropical depression leading to heavy rainfallfor the Ma river including:

In September 1962, a storm landed over Thanh Hoa provinces with highest speed of 30 $\mathrm{m} / \mathrm{s}$. After moving deep into land, it downgraded to become a tropical depression which lead to extreme rainfall and severe floods on the $\mathrm{Chu}$ river basin. The largest 3-day rainfall from 2729/IX/1962 were recorded as 542mm at Muong Hinh and $288 \mathrm{~mm}$ at Bai Thuong stations.

In 1973, during the end of August and the beginning of October, three continuing tropical storms (TS) and a tropical depression (TD) caused heavy rain and severe flooding in the upper, middle parts of $\mathrm{Ma}$ river and $\mathrm{Chu}$ river basins. The largest 7-day were recorded as $397 \mathrm{~mm}$ at Hoi Xuan, $457 \mathrm{~mm}$ at Lang Chanh, $542 \mathrm{~mm}$ at Thuong Xuan and Sao Vang, 639mm at Bai Thuong stations.

In 1996, the NIKI tropical storm landed over Thanh Hoa-Ninh Binh provinces on 23rd August, leading to extreme rainfall in the lower part of Ma and Buoi River with recording of 230$300 \mathrm{~mm}$.

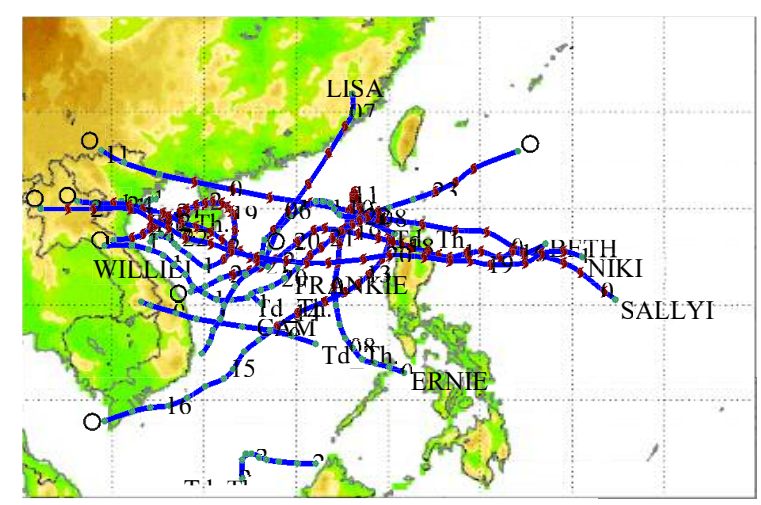

Fig. 4. Storm tracks in 1996 

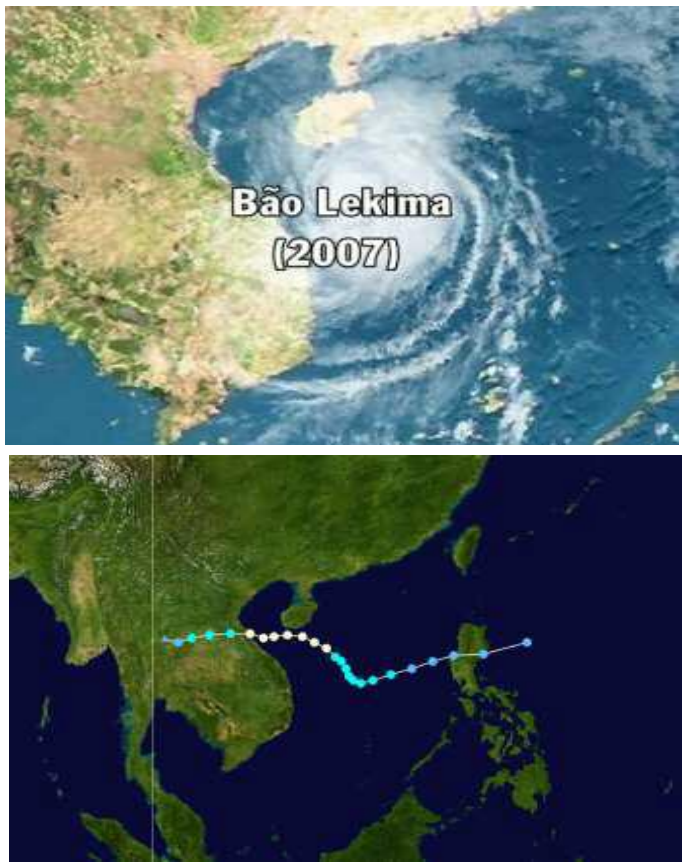

Fig. 5. Storm track of Lekima TS in 2007

In 2007, the Lekima typhoon hit to provinces of Quang Binh and Ha Tinh on the $3^{\text {rd }}$ October (Fig. 4). As results of TS and TS's circulation, extreme rainfall occurred in almost entire basin which were recorded the largest 5 -day rainfall as: $680 \mathrm{~mm}-990 \mathrm{~mm}$ in the middle and lower parts of Ma river, $800 \mathrm{~mm}-1100 \mathrm{~mm}$ in the middle and lower parts of Buoi river, $600-800 \mathrm{~mm}$ in the middle and lower parts of Chu river. His- torical flood was appeared on the mainstream of $\mathrm{Ma}$, Buoi and Chu rivers during this time.

\subsubsection{Formation causes of flood flow}

The Ma river basin is located in a tropical monsoon climate region. In the summer, weather disturbances in the basin cause heavy rain, resulting in severe flooding in the basin. The main critical weather conditions can be list as below:

- Inter tropical convergence zone (ITCZ) appearances during early and ending of summer.

- Storm appearances during early rainy season.

- Pole and dashed line fronts.

- Tropical cyclone and tropical depressions (TD) in the rainy season.

Through long-term historical data analysis, the $\%$ appearances of weather conditions causing heavy rainfall in Ma river basin is listed in Table 3. It can be seen that the occurrence of low-pressure trough line accounts for the high percentage of heavy to extreme rainfall in the Ma river basin. The most obvious evidence is a heavy rainfall - severe flood event appeared in the end of August 2018, which water levels at many stations were recorded new historical flood peaks as equal or exceeding the historic flood peaks in 2007.

Table 2. Statistics on critical weather patterns as results of severe flooding at Cam Thuy station on the Ma river basin (flood stages or high flood amplitudes)

\begin{tabular}{|c|c|c|c|c|c|c|}
\hline No. & $\begin{array}{c}\text { From } \\
\text { day/month }\end{array}$ & $\begin{array}{c}\text { To } \\
\text { day/month }\end{array}$ & Year & $\begin{array}{l}\text { Flood peak } \\
\quad(\mathrm{cm})\end{array}$ & $\begin{array}{c}\text { Flood } \\
\text { amplitude } \\
(\mathrm{cm})\end{array}$ & Critical weather patterns as results of heavy rain - severe flooding \\
\hline 1 & $10 / 09$ & $12 / 09$ & 2000 & 1788 & 451 & \\
\hline 2 & $22 / 07$ & $23 / 07$ & 2003 & 1742 & 555 & Tropical storm No. 3 (Goni) \\
\hline 3 & $28 / 08$ & $31 / 08$ & 2004 & 1668 & 393 & TD's affect in ITCZ \\
\hline 4 & $31 / 07$ & $01 / 08$ & 2005 & 1626 & 407 & TS No 2 (Washi) combination with South East strong wind \\
\hline 5 & $13 / 09$ & $15 / 09$ & 2005 & 1731 & 460 & ITCZ combination with South East strong wind \\
\hline 6 & $18 / 09$ & $19 / 09$ & 2005 & 1848 & 479 & TS No 6combination with ITCZ \\
\hline 7 & $27 / 09$ & $28 / 09$ & 2005 & 1834 & 524 & Typhoon No 7 (TY Damrey) \\
\hline 8 & $02 / 10$ & $05 / 10$ & 2007 & 2187 & 930 & TS No. 5 (Lekima) + South West Convergence wind \\
\hline 9 & $24 / 09$ & $27 / 09$ & 2008 & 1791 & 542 & TS No. 6 \\
\hline 10 & $29 / 10$ & $31 / 10$ & 2008 & 1739 & 457 & TS No. 7 \\
\hline 11 & $30 / 06$ & $07 / 07$ & 2009 & 1535 & 342 & Low pressure trough line in the North + low pressure $(1-7 / 7)$ \\
\hline 12 & $24 / 08$ & $29 / 08$ & 2010 & 1627 & 355 & ITCZ Circulation of TS No 3 (Mindulle) (21-25/8) + Low compressure line (26-29/8) \\
\hline 13 & $12 / 09$ & $15 / 09$ & 2010 & 1556 & 312 & Tropical high pressure + low depressure in the North \\
\hline 14 & $23 / 06$ & $25 / 06$ & 2011 & 1600 & 369 & TS No2 (Haima) \\
\hline 15 & 06/09 & $21 / 09$ & 2011 & 1581 & 312 & Cold mass air + Southeast wind $(19-21 / 9)$ \\
\hline 16 & 07/08 & $09 / 08$ & 2012 & 1699 & 364 & Low pressure trough line through the Northern part and low depressure up to $5000 \mathrm{~m}(6-10 / 8)$ \\
\hline 17 & $17 / 08$ & $19 / 08$ & 2012 & 1730 & 339 & TS No 5 (Kai-tak) - directly influence \\
\hline 18 & $06 / 09$ & 07/09 & 2012 & 1904 & 565 & $\begin{array}{l}\text { ITCZ through Center of Central Viet Nam + a weak Cold mass air + Eastern wind turbulence in } \\
\text { upper elevation }\end{array}$ \\
\hline 19 & $02 / 08$ & $03 / 08$ & 2015 & 1857 & 531 & Depression in the North + Southeast wind activity $(1-4 / 8)$ \\
\hline 20 & $17 / 09$ & $18 / 09$ & 2015 & 1919 & 668 & Northeast convergence wind + turbulence in the Eastern wind zone \\
\hline 21 & $28 / 08$ & $31 / 08$ & 2018 & 2220 & 629 & $\begin{array}{l}\text { Low pressure trough line with axis through the Northern part connecting with low depressure up to } \\
\text { the height of } 5000 \text { mmoving from East to West into Northern Delta and Thanh Hoa provinces } \\
\text { +subtropical high tongue encroaching to the West }(28-30 / 8)\end{array}$ \\
\hline
\end{tabular}


Nguyen Tien Kien et al./Vietnam Journal of Hydrometeorology, 2020 (04): 53-66

Table 3. Classification of percentage appearance capacities of weather conditions causing heavy rainfall-severe flooding on the Ma River

\begin{tabular}{cccccccc}
\hline $\begin{array}{c}\text { Classification } \\
\text { of rain levels } \\
(\mathrm{mm})\end{array}$ & Pole Front & $\begin{array}{c}\text { Trough } \\
\text { line }\end{array}$ & Dash line & TS & $\begin{array}{c}\text { Tropical } \\
\text { convergence }\end{array}$ & Cyclone & Unspecify \\
\hline $50-74.9$ & 10.8 & 43.2 & & 13.5 & 13.5 & 10.8 & 8.1 \\
$75-99.9$ & 7.1 & 42.9 & 3.6 & 17.9 & 17.9 & 1 & 7.1 \\
$100-149.9$ & 15.2 & 43.5 & 2.2 & 6.6 & 6.6 & 13 & 6.5 \\
$150-199.9$ & 25 & 20.8 & 4.2 & 4.2 & 4.2 & 20.8 & 4.2 \\
$200-299.9$ & 21.4 & 35.7 & & 14.3 & 14.3 & 14.3 & \\
$>300$ & 50 & 50 & & & & & \\
\hline
\end{tabular}

3.2. Timing and spatial rainfall distribution in the river basin

3.2.1. Current situation of rain gauge network in the basin

Almost hydro-meteorological stations in $\mathrm{Ma}$ river basin was built since 1960 upto now. However, a number of rain gauges and climate measurement stations established before 1954 such as Nhu Xuan (1928), Bai Thuong (1921), Thanh Hoa (1899), Hoi Xuan (1923) were discontinued measuring because of the war from 1944 to 1954. After the peaceful day, hydro-meteorological station network was expanded, but due to the war continuing and economic difficulties during 1979 and 1980, a lot of hydro-meteorological stations were downgraded or stopped. The stations with long-term time series can be mentioned as Thanh Hoa from 1899 - 1948, 1955- present or Hoi Xuan 1923 - 1944, 1960 present, Bai Thuong station 1921 - 1946, 1955 1990 to present. Until 2015, there are 6 weather stations and 42 rainfall gauges working well on the river basin. From 2016 upto now, the density of rain gauges has been improving by developing automatically stations. Currently, this network system is gradually being completed and preparing to operate therefore, the data from manual hydro-met stations are using in forecast operation or in research with stability and sufficient time series of data.

Rain gauges distribution in the Ma river basin illustrated in Fig. 2 in which there are 02 meteorological stations in upstream named: Tuan Giao and Song Ma and no stations or rain gauges in Laos. In the downstream area belong Thanh Hoa and Nghe An provinces, there is a quite density ofrain gaugesand meteorological stations. Besides, a high density of rain gauges in the delta and coastal areas showed an unevenly distribution of station network in the Ma river basin.

\subsubsection{Spatial rainfalldistribution in the $M a$} river basin

As mentioned above, rainfall regime in the Ma river basin is divided into three different characteristics: the upstream in the Northwest of Northern part regime; the Chu river basin in the Northern Central rainfall regime; downstream and delta areaas similaras the rainfall regime of Northern delta area.

Due to topographical conditions, the upper part of the river basin is located in the high mountain ranges and sheltered from the wind with low rainfall. The average annual rainfall at Song Ma station is around $1150 \mathrm{~mm}$ and at Son $\mathrm{La}$ is $1444 \mathrm{~mm}$. In the middle part of Ma river, the annual rainfall increases up to $1700-1800 \mathrm{~mm}$ at Ba Thuoc, Cam Thuy, Hoi Xuan and Muong Hinh. The middle area of Chu river, annual rainfall is from $1900 \mathrm{~mm}$ to $2200 \mathrm{~mm}$ at stations of Thuong Xuan, Bat Mot.

Regarding to basin characteristics of $\mathrm{Chu}$ and Am rivers, the high mountain ranges surrounding of the left and right sides are very convenient for catching the wind, especially when appearances of storms. The upstream of $\mathrm{Chu}$ and $\mathrm{Ma}$ rivers belong Lao's territory, there is no information and hydro-met data for research and analysis. The lower part of Ma riveris the disturbance area between rainfall regimes of the Northern part and the Northern Central. Regarding to spatial dis- 
tribution, there are two rainfall centers in the river basin as Ba Thuoc - Quan Hoa and Thuong Xuan in which the annual rainfall in Thuong Xuan is much bigger than that of Ba Thuoc Quan Hoa. Besides, in the upper part of Ma river, there are small rainfall centers located river valley Song Ma district, Son La province.

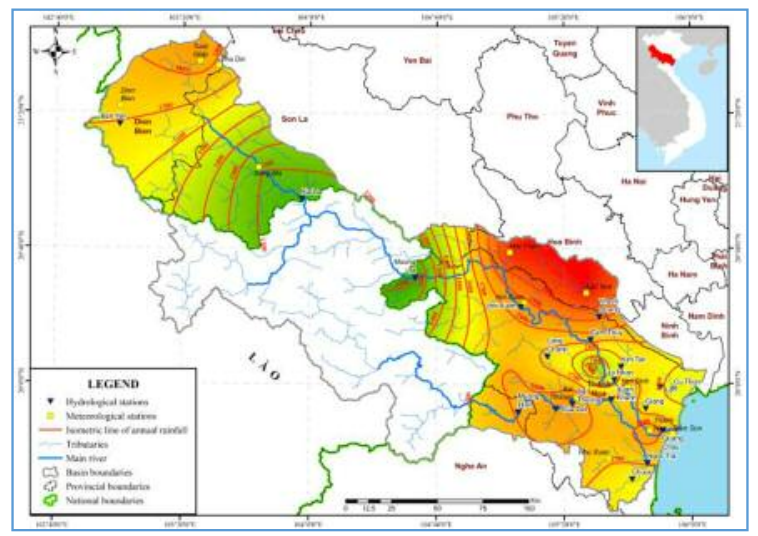

Fig.6. Annual rainfall distribution on Ma river basin (NCHMF - data updated until 2017)

Annual rainfall in the basin varies from $1100 \mathrm{~mm} /$ year to $1860 \mathrm{~mm} /$ year. There are two distinct seasons in a year as dry season and rainy season. The rainy season in the Ma river's upstream usually starts in May and ends in November while the rainy season on the Chu river starts at the end of June and ends at the beginning of December. Following long-term statistics, total rainfall of the two seasons has a significantly difference in which total rainfall in the rainy season accounts for $65-80 \%$ of the total annual rainfall while that of dry season only accounts for $30-35 \%$ of the total annual rainfall.

\subsubsection{Timing rainfall distribution in Ma river} basin

The Ma river basin is located in the tropical monsoon climate, therefore rainy season associated with activities of Southeast monsoon, Lao windyas usually from May to October with hot and humid weather and storm appearances as well. While dry season is associated with the northeast monsoon period from December to April. Rainfall regime in the Ma river basin has three specific properties with different starting and ending times of the rainy season:

+ The upper part of the Ma river mainstream has a Northwest climate regime, so the rainy season usually starts earlier and ends earlier than that of the Central region of Viet Nam;

+ The Chu river basin is located in the rainy area of the Northern Central region of Viet Nam, the rainy season arrives 10 to 20 days later and ends 10 to 15 days later than the rainy season in the Northern part of Viet Nam;

+ The Ma river delta area has the nuance of the Northern part rainyregime; the heaviest rainfall is usually concentrated in August and September in the year.

The monthly rainfall distribution is uneven, the total rainfall in the months of rainy season in many areas accounts for $80-85 \%$ of the total annual rainfall, the rest of $15-20 \%$ in the months of dry season (Fig.11).The largest annual rainfall areas in Ma river basin canbe mentioned as Lang Chanh, Bat Mon, Van Xuan and Thuong Xuan in the upper reaches of the Am and Chu rivers with an annual rainfall of $2000 \mathrm{~mm}-2200 \mathrm{~mm}$. From May to June, due to the convergence of the Southwest monsoon and the monsoon winds, the average monthly rainfall increases markedly from 10 to $20 \%$ of the annual rainfall and sometimes leading to minor floods during this time. 


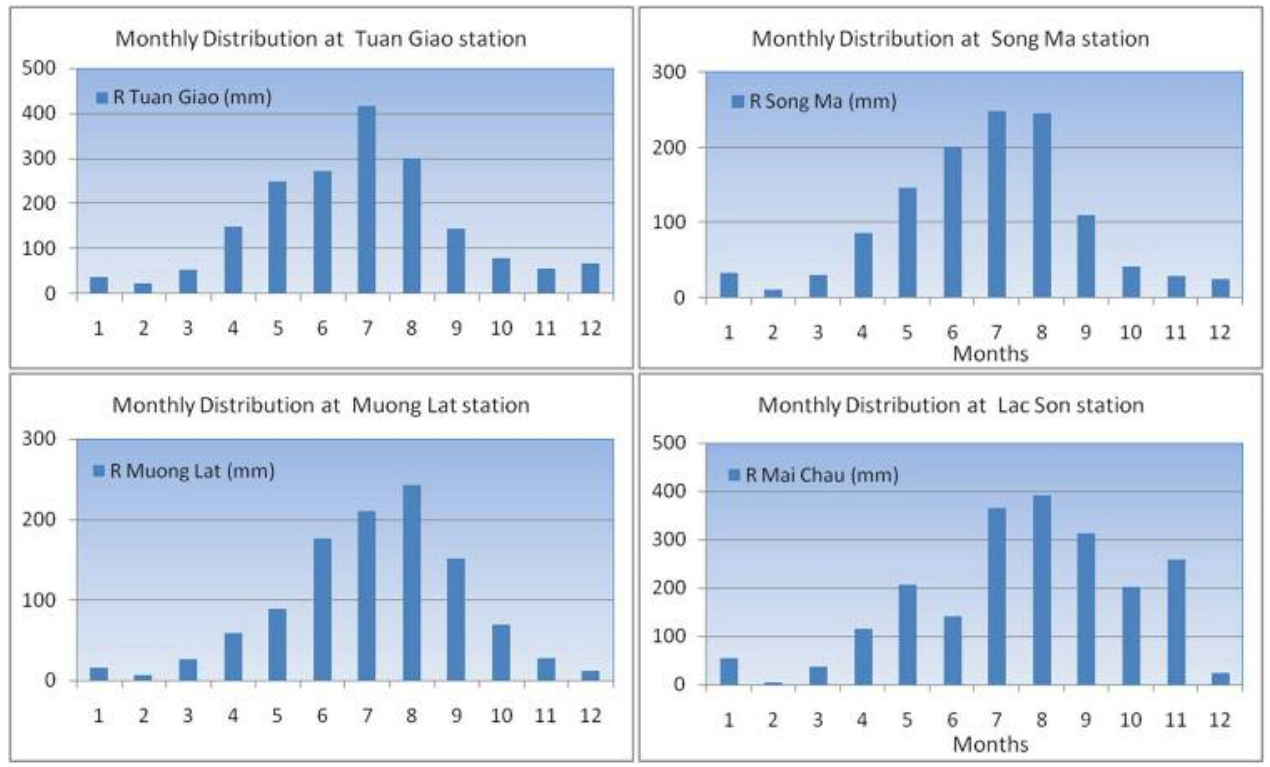

Fig. 7. Monthly long-term average of rainfalldistribution in the upper reach of Ma River basin
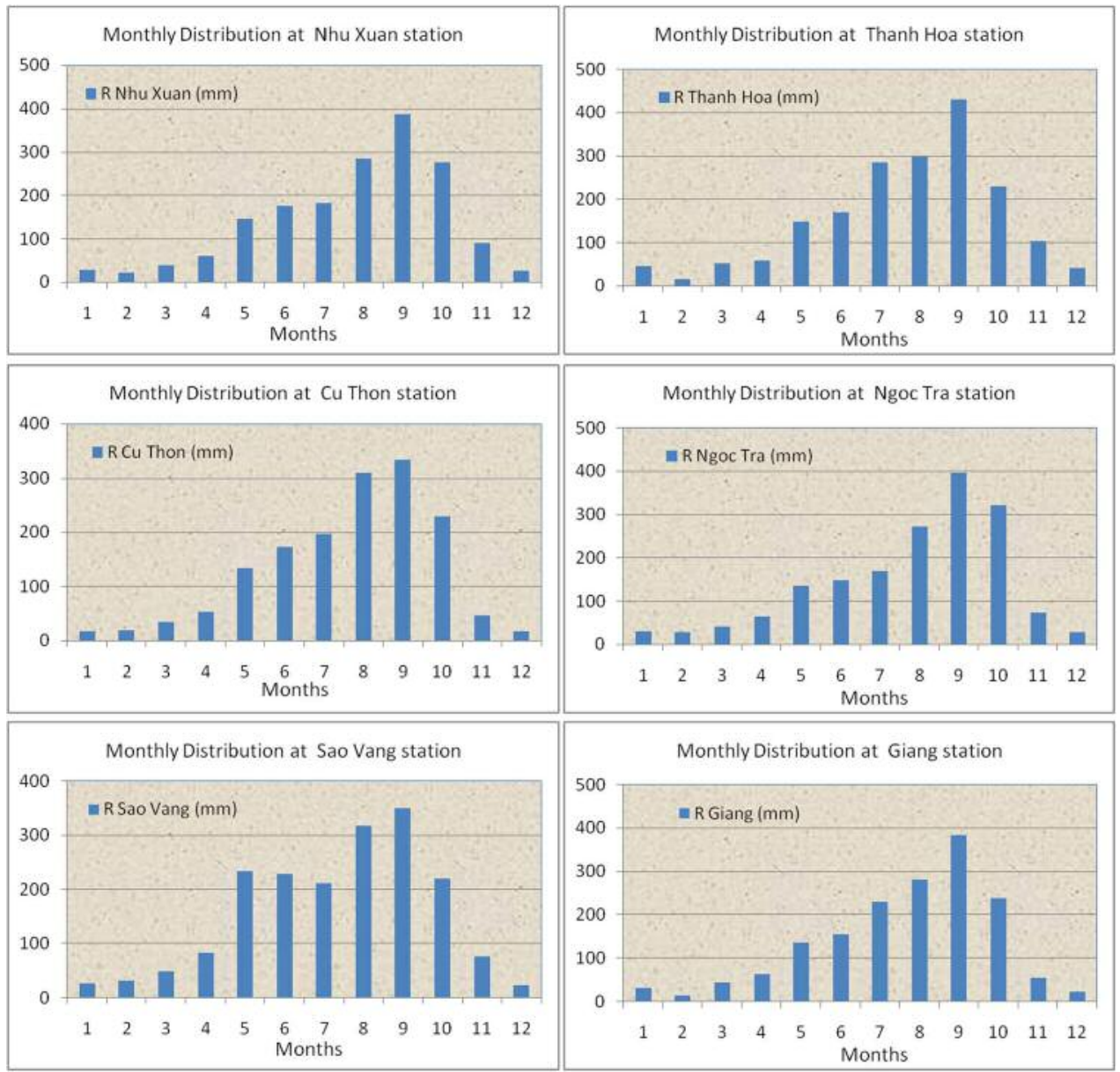

Fig. 8. Monthly long-term average of rainfall distribution in the lower reach of Ma River basin 

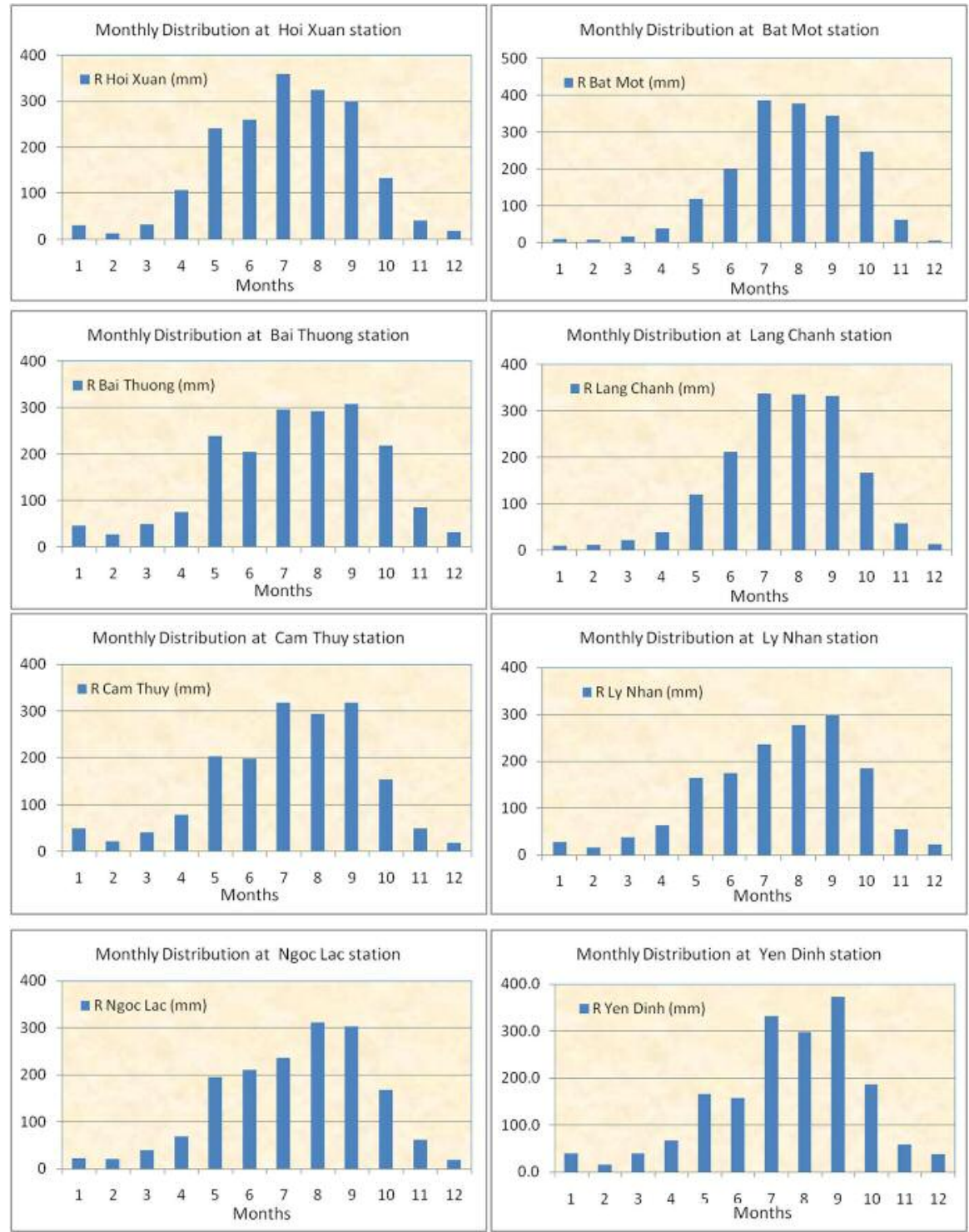

Fig. 9. Monthly long-term average of rain fall distribution in the middle reach of Ma River basin
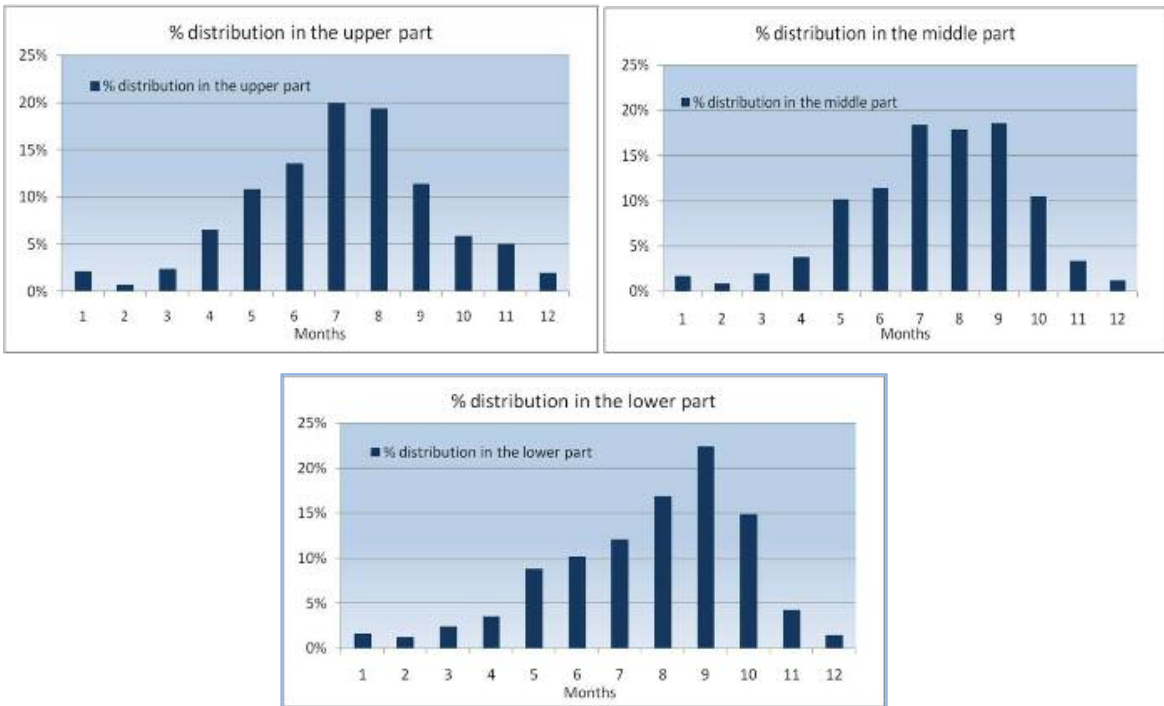

Fig. 10. Percentages distribution of monthly long-term average precipitation from upper to lower reaches of the Ma River basin 

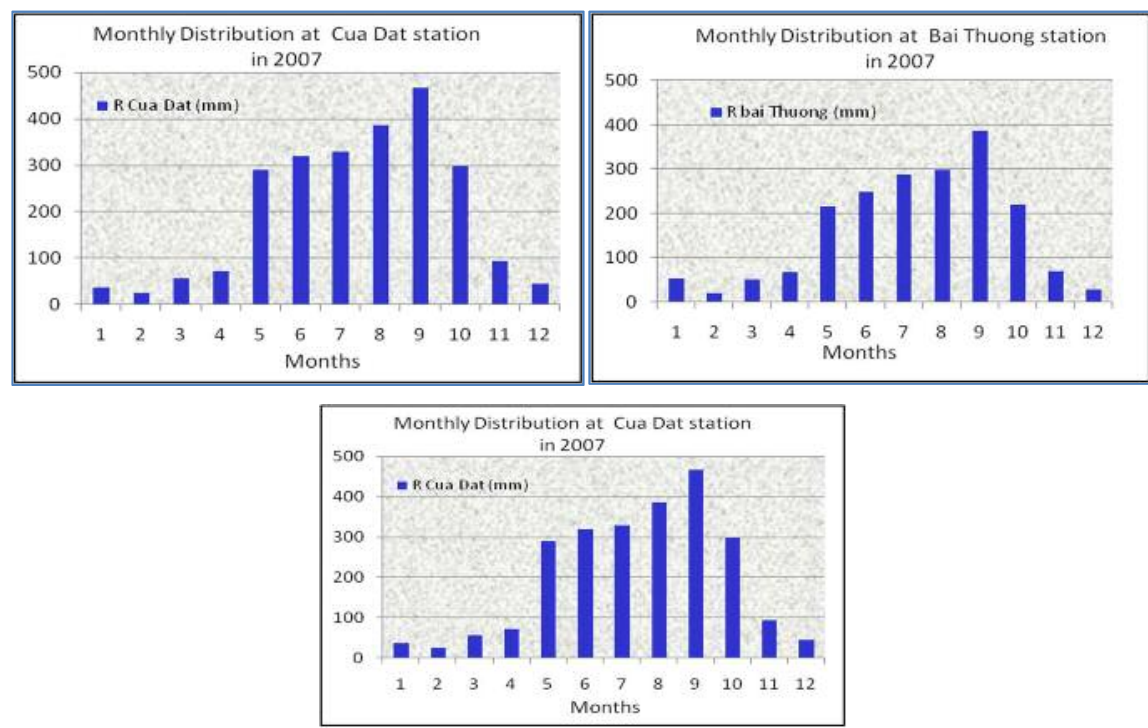

Fig. 11. Monthly rainfall distribution in the upper and middle reaches of the Chu River

Based on the long-term historical time series data (around 1963 to 2017), monthly rainfall distribution at upper to lower reaches of the Ma River are illustrated in Fig. 8 to Fig. 10. In the northern part of the upper reaches of the Ma river basin, due to the early rainy season, the average monthly rainfall is likely over $100 \mathrm{~mm}$ since April and increases gradually up to its maximum during July and August, then stating to reduce from September. Therefore, floods in Ma river's upstream and Northern part tributaries often occur the largest situation in August, which is almost coinciding with the occurrence of big floods in the North of Viet Nam.

Meanwhile, in the middle, lower parts and the southern part of the Ma River basin, the rainy season is gradually shifted that the total rainfall over $100 \mathrm{~mm}$ usually starts in May and the highest average monthly appears in September from $300-450 \mathrm{~mm}$, accounting for $20-22 \%$ of the annual rainfall. The years of heavy rain are often influenced by storms such as 1962, 1963, 1973, 1975, 1980, 1996 and 2007. These are the years occurred extreme rainfall and severe flooding on the Ma river basin. Fig. 11 shows a clearly illustration of the distribution percentages of monthly precipitation from upper to lower reaches along Ma River basin.

The amount and distribution of monthly rain- fall at a number of presentative stations in the basin are illustrated in Fig. 6 based on long-term time series. However, from the last 10 years, heavy rainfall on the Chu river in May have been occurred more frequently. Fig. 11 shows that total rainfall at stations located in middle part of Chu River in May are almost over $100 \mathrm{~mm}$ and somehow equal to total rainfall in June.

\section{Conclusion and suggestions}

The climate regimes of different parts and small basins belong the Ma river basin are different and abundant, therefore the rainfall and flood regime in the basin is very complicated. The hydro-meteorological station network in the basin is unevenly distributed with a quite high density of stations concentrating on the lower reach of the $\mathrm{Ma}$, Chu and Am rivers. There are no information and data in the upper part of the Chu river in Lao PDR, and a limited number of stations in the upper reach of Ma river where is the high mountainous area in North of Vietnam. This is a challenge on flood forecasting at provincial and national forecast centers for these areas when facing the characteristics of mountainous floods with short period of water concentration and large flood amplitude.

Currently, there are many sources of satellite 
rainfall estimates (SRE) (referred to as satellite rainfall) having high-quality spatial and temporal resolution, which are studied and applied more and more in hydrological and water resources forecasts. With the advantage of being able to cover the entire river basin, satellite rain covers the entire space of missing or few hydromet stations and will be an important source of input data for the hydrological model in flood forecast.

One of the satellite rainfall products have been exploited and used at the National Center for Hydrological and Meteorological Forecasting (NCHMF) is JAXA's Japan-based GSMaP which is a data source with high spatial and timing resolution, small latency in comparation with real-time rainfall. GSMaP is a global satellite program based on TRMM rainfall maps and other products with the ability to provide hourly rainfall with high resolution of $0.10 \times 0.10$ with near real-time data GSMaP_NRT.

GSMaP data can be able to cover a large area however some main disadvantages can be mentioned as: 1) The product of GSMAP_NRT (near real-time satellite rainfall data) have a delay of 34 hours compared to the observation; 2) The problem of disturbance due to topographic influences.

Therefore, with the high mountainous areas like in Northern Central of Vietnam, GSMaP cannot completely replace data from ground truth stations but can fill up for lacking data areas or areas without observation. The use of satellite rainfall data is one of the remarkable solutions in the study of river basins, in hydrological forecasts for areas where data is lacking or not available.

Besides, using hydrological model of distribution parameters is a high recommendation because it can be able to integrate satellite rainfall and other remote sensing data sources.

\section{References}

1. Chow, V.T., 1964. Handbook of applied hydrology: a compendium of water-resources technology. $1^{\text {st }}$ ed. New York, USA: McGrawHill, Inc.

2. Dirks, K.N., Hay, J.E., Stow, C.D., 1998. High resolution studies of rainfall on Norfolk Island Part II: interpolation of rainfall data. Journal of Hydrology, 208: 187-193.

3. Fotheringham, A.S., Brunsdon, C., Charlton, M., 2002. Geographically weighted regression: the analysis of spatially varying relationship. Wiley, New York.

4. Goovaerts, P., 1999. Using elevation to aid the geostatistical mapping of rainfall erosivity. Catena, 34(3-4): 227-242.

5. Jeffrey, S.J., Carter, J.O., Moodie, K.B., Beswick, A.R., 2001. Using spatial interpolation to construct a comprehensive archive of Australian climate data. Environmental Modelling \& Software, 16(4): 309-330.

6. Lam, N.S.N, 1983. Spatial interpolation methods: a review. American Cartographer, 10(2): 129-149.

7. Lloyd, C.D., 2005. Assessing the effect of integrating elevation data into the estimation of monthly precipitation in Great Britain. J. Hydrol., 308(1-4): 128-150.

8. Ly, S., Charles, C., Degré, A., 2013. Different methods for spatial interpolation of rainfall data for operational hydrology and hydrological modeling at watershed scale. A review. Biotechnology, Agronomy, Society and Environment, 17(2): 392-406.

9. Li, J., Heap, A.D., 2008. Spatial interpolation methods: a review for environmental scientists. Geoscience Australia, Record. Geoscience Australia, Canberra.

10. Masih I., Maskey S., Uhlenbrook S.\& Smakhtin V., 2011. Assessing the impact of areal precipitation input on streamflow simulations using the SWAT model. Journal of the American Water Resources Association, 47(1): 179-195.

11. National Centre for Hydro-Meteorological Forecasting (NCHMF) 2000 to 2017. Annual Hydrological and Meteorological characteristic reports for year of 2000 - 2017. Viet Nam Me- 
teorological and Hydrological Administration, Ha Noi, Viet Nam.

12. Nalder, I.A., Wein, R.W., 1998. Spatial interpolation of climatic normals: test of a new method in the Canadian boreal forest. Agricultural and Forest Meteorology, 92(4): 211-225.

13. Phung, N. X., et al., 2014. Hydrological report - Review of Ma river basin irrigation planning project. Institute of Water resources planning (IWRP), Ha Noi, Viet Nam.

14. Price, D.T., McKenney, D.W., Nalder, I.A., Hutchison, M.F., Kesteven, J.L., 2000. A comparison of two statistical methods for interpolation of Canadian monthly mean climate data. Agricultural and Forest Meteorology, 101(2-3): 81-94.
15. Report of Ma river flood forecasting projects 2014 to2017. Division of hydrological forecast for Central, Highland and the South of Viet Nam, National Centre for Hydro-Meteorological Forecasting, Ha Noi, Viet Nam.

16. Ruelland, D., Ardoin-Bardin, S., Billen, G., Servat, E., 2008. Sensitivity of a lumped and semi-distributed hydrological model to several methods of rainfall interpolation on a large basin in West Africa. Journal of Hydrology, 361(1-2): 96-117.

17. Yeh, H.C., Chen, Y.C., Wei, C., Chen, R.H., 2011. Entropy and kriging approach to rainfall network design. Paddy and Water Environment, 9: 343-355. 